\title{
Eighteen-month-olds' memory for short movies of simple stories
}

\section{Osman Skjold Kingo and Peter Krøjgaard}

Center on Autobiographical Memory Research, Department of Psychology and Behavioural Sciences, Aarhus University, Bartholins Allé 9, Building 1340, 8000 Aarhus C, Denmark.

NOTICE: This is the accepted version of the following article: Kingo, O.S., \& Krøjgaard, P. (2015). Eighteen-month-olds' memory for short movies of simple stories, Scandinavian Journal of Psychology, DOI: 10.1111/sjop.12201, which has been published in final form at https://dx.doi.org/10.1111/sjop.12201

Changes resulting from the publishing process, such as peer review, editing, corrections, structural formatting, and other quality control mechanisms may not be reflected in this document. Changes may have been made to this work since it was submitted for publication.

Corresponding Author:

Osman S. Kingo,

Bartholins Allé 9

Center on Autobiographical Memory Research, Department of Psychology and Behavioral Sciences, Aarhus University, DK-8000 Aarhus C, Denmark

Phone: +45 87165862 (direct)

Fax: +4587164401

Email: osman@psy.au.dk 
This is the accepted version of the following article: Kingo, O.S., \& Krøjgaard, P. (2015). Eighteen-month-olds' memory for short movies of simple stories, Scandinavian Journal of Psychology, which has been published in final form at https://dx.doi.org/10.1111/sjop.12201

\section{Acknowledgement}

We would like to thank Jonna Jelsbak Dahl, Ida Marie Lautrup, Inger Birchall Nielsen, and Trine Sonne for collecting the data, Søren Risl $\varnothing v$ Staugaard for setting up the eye-tracker equipment, and Kim Plunkett and Ocke-Schwen Bohn for fruitful discussions regarding this study. Finally, we thank all participating infants and their parents for their time and enthusiasm.

The present study was supported by the Danish National Research Foundation (Grant No DNRF93) and the MindLab UNIK initiative which is funded by the Danish Ministry of Science, Technology, and Innovation. 


\begin{abstract}
This study investigated twenty four 18-month-olds' memory for dynamic visual stimuli. During the first visit participants saw one of two brief movies (30 seconds) with a simple storyline displayed in four iterations. After 2 weeks, memory was tested in the Visual Paired Comparison paradigm in which the familiar and the novel movie were contrasted simultaneously and displayed in two iterations for a total of 60 seconds. Eye-tracking revealed that participants fixated the familiar movie significantly more than the novel movie, thus indicating memory for the familiar movie. Furthermore, time-dependent analysis of the data revealed that individual differences in the looking-patterns for the first and second iteration of the movies were related to individual differences in productive vocabulary. We suggest that infants' vocabulary may be indicative of their ability to understand and remember the storyline of the movies, thereby affecting their subsequent memory.
\end{abstract}




\section{Eighteen-month-olds' memory for short movies of simple stories}

Studying the memory of infants is constrained by the fact that we cannot rely on verbal reports of these memories in our investigations. Consequently, we have to employ a range of non-verbal behavioral methods to disentangle the dynamics of infant memory (Hayne, 2004). One of these, the visual paired comparison (VPC) procedure ${ }^{1}$, has been used in many variations and seems promising from a developmental point of view, since it is applicable for age-groups ranging from infancy to adulthood (Morgan \& Hayne, 2011; Richmond, Sowerby, Colombo, \& Hayne, 2004). In the VPC procedure, two visual stimuli are presented simultaneously: one that has been presented previously (the familiar stimulus) and one that is novel. Looking-times above chance level to either the familiar or the novel stimuli are then taken as memory for the familiar stimuli (Richmond, Colombo, \& Hayne, 2007).

As with all lab-based experimental studies, the choice of specific stimuli can have an enormous impact on the results. Often, the stimuli in VPC studies have been static displays of some sort, but it has been argued that dynamic-event stimuli allows for better generalization of data to memory for real world events since the real world is dynamic in nature (Bahrick, Gogate, \& Ruiz, 2002). However, the dynamic stimuli used in VPC studies have often been either moving abstract shapes (Courage \& Howe, 1998, 2001), single objects in simple motion (e.g. Bahrick \& Pickens, 1995; Bahrick, Hernandez-Reif, \& Pickens, 1997), displays with very minor movement like a face blinking its eyes or moving its mouth (Morgan \& Hayne, 2011), morphing faces (Richmond et al., 2004), or actors performing simple repetitive activities like brushing hair (Bahrick et al., 2002; Bahrick \& Newell, 2008). Although dynamic in nature, these stimuli may fail to capture important aspects of the real world experience such as the

\footnotetext{
${ }^{1}$ Sometimes referred to as the Visual Recognition Memory (VRM) procedure or the novelty-preference task.
} 
This is the accepted version of the following article: Kingo, O.S., \& Krøjgaard, P. (2015). Eighteen-month-olds' memory for short movies of simple stories, Scandinavian Journal of Psychology, which has been published in final form at https://dx.doi.org/10.1111/sjop.12201

interconnections of agency, intentionality, actions, and outcomes - aspects that are important and noted in infant experience (Baldwin, 2000; Baldwin, Baird, Saylor, \& Clark, 2001; Meltzoff, 1995; Tomasello, 1999). In addition, these aspects are essential in the narration of autobiographical memories later in childhood (Reese, 1999), as well as in adulthood (Conway \& Pleydell-Pearce, 2000).

To better capture some of these important aspects of real world experiences, we used short and simple cartoon stories as the dynamic stimuli in the present VPC study. We tested 18-month-olds' memory for these after a delay of two weeks. We chose this age-group because this is an age of both rapid vocabulary growth (Oates \& Grayson, 2004) and important changes in self-awareness, as evidenced by mirror-self recognition (Bard, Todd, Bernier, Love, \& Leavens, 2006; Lewis \& Brooks-Gunn, 1979) and related tests (Moore, Mealiea, Garon, \& Povinelli, 2007). We therefore thought that infants at the age of 18 months would begin to possess the skills necessary for a meaningful processing of the storyline in the presented stimuli (see below).

The typical preference-pattern for visual recognition memory has been suggested to follow four phases, such that short retention intervals (associated with strong memory traces) produce novelty preferences, intermediate retention intervals produce null preferences, long retention intervals (associated with weak memory traces) produce familiarity preferences, and very long retention intervals (associated with inaccessible memory traces) produce null preferences again. The specific transition points between these suggested phases depend on various factors such as the age of the infants, the specific material to be remembered, and the degree of encoding at the first exposure (Bahrick \& Pickens, 1995). For the present study we expected to find an overall familiarity preference, if any, since a delay of two weeks is much longer than the typical "short" retention interval (e.g. one minute in Bahrick \&Pickens, 1995). In addition, Morgan and Hayne (2011) found that one- and two-year-olds showed no novelty or familiarity preference for dynamic stimuli in a VPC study after a delay of one week, but based 
This is the accepted version of the following article: Kingo, O.S., \& Krøjgaard, P. (2015). Eighteen-month-olds' memory for short movies of simple stories, Scandinavian Journal of Psychology, which has been published in final form at https://dx.doi.org/10.1111/sjop.12201

on the Bahrick and Pickens' (1995) four-phase model, predicted that a familiarity preference would be found after longer delays.

However, to complicate matters, preferential looking to familiar or novel material often shifts during the test-phase if the test-phase is extended and/or if several test trials of the same material are included (Houston-Price \& Nakai, 2004; Snyder, Blank, \& Marsolek, 2008). Results from a recent study in our lab (Kingo, Staugaard, \& Krøjgaard, 2014) confirm this finding. Roder, Bushnell, and Sasseville (2000) also found that infants preferred the familiar stimuli initially, but then shifted towards a novelty preference during the course of the test-phase. Interestingly, this was only so for meaningful material (objects or faces). When tested with abstract (kaleidoscope) patterns, infants did not respond with an initial familiarity preference prior to the novelty preference. Although no firm conclusions were made based on these differences, Roder et al. did establish that the degree to which the infants found the stimuli meaningful affected the pattern of familiarity and novelty preferences during the course of the test-phase. They also argued that infants would tend to follow the familiarity-to-novelty pattern, but that the specific timing of such a shift would differ on an individual level.

The use of dynamic meaningful stimuli in the form of short movies with a storyline, as in the present study, complicates the picture, since such a dynamic stimulus may attract the infants' attention differently at different points in time - especially when contrasted to another dynamic stimulus during the test. However, such a contrast would still be a familiar stimulus contrasted with a novel one. So, following the above, we expected preferences to shift during the test-phase of the current study as well. In addition, and based on the suggestions from Roder et al. (2000), we hypothesized that we would find individual differences in the timing of such shifts that would be related to the infants' conceptual development - more specifically the extent to which individual infants experienced the cartoon movies to be meaningful sequences or narratives in contrast to non-conceptual perceptual displays. So, as an 
This is the accepted version of the following article: Kingo, O.S., \& Krøjgaard, P. (2015). Eighteen-month-olds' memory for short movies of simple stories, Scandinavian Journal of Psychology, which has been published in final form at https://dx.doi.org/10.1111/sjop.12201

approximation of semantic/conceptual development, we included a measure of vocabulary in the study. Vocabulary has been found to correlate with early categorizations skills (Gopnik \& Meltzoff, 1987, 1992) and has been argued to relate importantly to conceptual development in general (Waxman \& Gelman, 2010). Furthermore, productive vocabulary has been found to be related to the ability to process and remember event sequences (e.g. Bauer \& Wewerka, 1995; McGuigan \& Salmon, 2004).

It was our hope that using the dynamic short stories in the VPC paradigm would enable us to shed light on the usefulness of this paradigm for testing infants' memory for events. Additionally, we wanted to investigate the impact of conceptual development on such memory, as expressed by visual preference. We suspected that displaying each story twice at test (see below) would allow us to detect preference-changes above and beyond the variation to be found within the duration of a single iteration of the story. If so, we would be able to compare such cross-iteration changes with infants' conceptual development as expressed by vocabulary.

\section{Method}

\section{Participants}

Twenty-four healthy 18 -month-olds ( $M_{\text {age }}=18.08$ months, $S D=.24,16$ were female) were recruited from the Aarhus area in Denmark via registers from the National Board of Health. All participants came from families with middle to upper-middle income and had parents with at least a high school degree and most often a higher education. Three additional infants were tested but excluded from the analysis because their sampled looking-time to the stimuli was more than three standard deviations below the group mean of either the full test period (2) or the first or second half of the test (1). 
This is the accepted version of the following article: Kingo, O.S., \& Krøjgaard, P. (2015). Eighteen-month-olds' memory for short movies of simple stories, Scandinavian Journal of Psychology, which has been published in final form at https://dx.doi.org/10.1111/sjop.12201

\section{Equipment}

A Tobii X120 eye-tracker was used to record participants' fixations at $60 \mathrm{~Hz}$ (with $0.5^{\circ}$ accuracy) on a $30^{\prime \prime}$

LCD widescreen. The total visual angle of the screen was 40 (width) $\times 25$ (height) ${ }^{\circ}$, while the visual angle

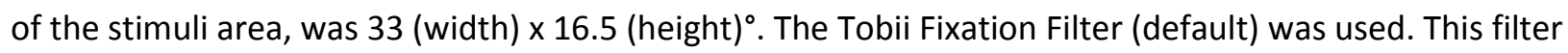
detects quick changes in the gaze point signal using sliding averaging and thus distinguishing between fixations and saccades. Interpolation of samples was used when data samples were missing (e.g. during a blink). A 5-point calibration was performed using Tobii Studio calibration for infants (five small dancing Teddies, one in each corner of the screen and one centrally). Stimulus presentation was performed with the E-prime software.

\section{Materials}

The stimuli movies were two custom-made short cartoons (see Figure 1), each with a duration of 30 seconds and of the same size. One movie, the Snowman, is set in a winter landscape. A snowman enters the scene and jumps towards a tall hat lying on the ground. The snowman looks down at the hat and starts jumping up and down. For each jump the hat bumps higher and higher into the air, until it finally lands on the head of the snowman. The snowman smiles and leaves the scene. The other movie, the $\mathrm{Crab}$, is set at a beach. A crab enters the scene and moves towards a ball lying on the ground. The crab starts playing with the ball and juggling it, until one of its claws punctures the ball causing it to deflate and fall to the ground. The crab looks directly at the "camera" and then leaves the scene. There was no sound to any of the movies.

In addition, all parents filled out a standardized Danish version of the MacArthur-Bates Communicative Development Inventory: Words and Gestures (CDI), and handed it in when coming back for the second visit. 
Figure 1

\section{Design and Procedure}

At both visits $\left(T_{1}\right.$ and $\left.T_{2}\right)$, infants were seated in a car seat mounted on top of an adjustable chair. The eyes of the infant were approximately 70 centimeters from the eye-tracker, and level with the center of the screen. At $\mathrm{T}_{1}$, one of the two movies (Snowman or Crab) was displayed for each infant in the center of the screen four consecutive times, for a fixed total of 120 seconds. Looking-time was not measured during $T_{1}$ but all children would generally look at the screen for the majority of the 120 seconds. Because there was no other interesting or salient features in the booth we did not find it meaningful to measure $T_{1}$ looking-time since even a loss of interest would for the most part result in looking at the screen in lack of other options. Half of the infants ( 8 females, 4 males) saw Snowman and half ( 8 females, 4 males) saw Crab, to rule out that any patterns in the results would be driven by differences on stimulus appeal. Two weeks later $(M=14.00$ days, $S D=.83$ days $)$, at $T_{2}$, infants saw both movies simultaneously side by side two consecutive times, for a total of 60 seconds. Left/right positioning of the familiar and novel movies (either Snowman or Crab), was counterbalanced across infants. The infants were eye-tracked during the presentation at $\mathrm{T}_{2}$ and two Areas of Interest (AOI's) where drawn for data analysis: each covering one of the simultaneous movies.

\section{Results}

The primary dependent measure was the proportion of time spent looking at the novel stimulus during the test. This is the most widely used dependent measure in VPC studies. A proportional novelty- 
This is the accepted version of the following article: Kingo, O.S., \& Krøjgaard, P. (2015). Eighteen-month-olds' memory for short movies of simple stories, Scandinavian Journal of Psychology, which has been published in final form at https://dx.doi.org/10.1111/sjop.12201

preference score was calculated by dividing the total looking-time to the novel movie with the total looking-time to both movies, thus producing a novelty-preference score between 0 and 1 . Preliminary analyses revealed no gender differences in the novelty-preference score $\left(M_{\text {prop_female }}=.38, S D=.23\right.$; $\left.M_{\text {prop_male }}=.26, S D=.19.\right) t(22)=1.31, r=.27$, and no differences in the absolute looking-time for the two different stimuli movies $\left(M_{\text {Snowman }}=23.78\right.$ seconds, $S D=14.63 ; M_{\text {crab }}=29.96$ seconds, $\left.S D=14.26\right)$ $t(23)=1.01, r=.22$, all $p^{\prime} s>.1$. In addition, there were no significant gender differences in the CDI scores $\left(M_{\text {Female }}=123, S D_{\text {Female }}=98, M_{\text {Male }}=52, S D_{\text {Male }}=34\right.$, Mann-Whitney $U=42 z=-1.35, r=-.27$. $)$

The main analysis compared the novelty-preference score for the full test-phase (60 seconds) to a hypothetical mean of .5 . The mean novelty-preference score was .34 $(S D=.22)$ : significantly lower than $.5: t(23)=-3.56, p<.002, r=.60$. The infants thus showed a clear preference for the familiar movie (see also Figure 2). There were no significant differences in the novelty-preference scores for the $1^{\text {st }}(0$ $30 \mathrm{sec})$ and $2^{\text {nd }}(30-60 \mathrm{sec})$ iteration of the movies during the test-phase $\left(M_{1 \text { st_iteration }}=.32, S D=.21\right.$; $\left.M_{\text {2nd_iteration }}=.37, S D=.26, t(23)=-1.33, p>.1, r=.27\right)$ and no difference in the total looking time to both movies between the $1^{\text {st }}$ and $2^{\text {nd }}$ iteration $\left(M_{1 \text { st_iteration }}=27.44, S D=1.62 ; M_{2 \text { nd_iteration }}=26.31, S D=2.90\right.$, $t(23)=1.85, p=.078, r=.36)$.

Figure 2

To investigate the possible relation between memory for the movies and vocabulary, we initially ran a correlational analysis of the novelty-preference score and the productive vocabulary score. This analysis did show a weak tendency for higher vocabulary to be associated with low novelty-preference, but it was non-significant, $r=-.35, p=.096$. However, we had hypothesized changes in the novelty- 
This is the accepted version of the following article: Kingo, O.S., \& Krøjgaard, P. (2015). Eighteen-month-olds' memory for short movies of simple stories, Scandinavian Journal of Psychology, which has been published in final form at https://dx.doi.org/10.1111/sjop.12201

preference scores during the full test-phase and that such changes might relate to vocabulary.

Specifically, we were interested in differences between the $1^{\text {st }}$ and $2^{\text {nd }}$ iteration of the movies during test. Therefore, we repeated the correlational analysis above, but separately for each of the two iterations of the movie. For the first iteration there was no significant correlation between vocabulary and the novelty-preference score, $r=-.083, p=.701$. For the second iteration, however, this correlation was significant, $r=-.464, p=.022$, meaning that a higher vocabulary was associated with a smaller novelty-preference (i.e. a higher familiarity-preference). Then, to more directly investigate the differences between the two iterations, we calculated a "change value" signifying the difference in the novelty-preference scores from the $1^{\text {st }}$ to the $2^{\text {nd }}$ iteration of the movies by subtracting the noveltypreference scores of the 1st iteration from those of the $2^{\text {nd }}$. We then ran a correlational analysis for this change value and productive vocabulary and found a significant correlation, $r=-.47, p<.02$, meaning that a lower vocabulary score was associated with a greater increase in novelty-preference (i.e. a decrease in familiarity-preference) from the $1^{\text {st }}$ to the $2^{\text {nd }}$ iteration of the movies. These analyses reveal that infants with a lower vocabulary score tended to show a reduced familiarity-preference at the $2^{\text {nd }}$ iteration, whereas infants with a higher vocabulary tended to maintain the familiarity preference. Solely for the purpose of illustrating the dynamics captured by this correlational analysis, we split the infants into a higher and lower vocabulary group (by the median) as seen in Figure 3. Please note that the vocabulary scores of these two groups were only higher or lower relative to the other infants in the study - not necessarily relative to the norms of the CDI. As such, this grouping could only qualify and explore the individual differences found by the correlational analysis for the participants of this particular study. It is evident from this graph that the higher and lower vocabulary groups are comparable during the $1^{\text {st }}$ iteration, but differ markedly during the $2^{\text {nd }}$ iteration. The lower vocabulary group shows a familiarity-preference during the $1^{\text {st }}$ iteration and then reverts to a null-preference in the $2^{\text {nd }}$. The higher vocabulary group also shows a familiarity-preference during the $1^{\text {st }}$ iteration but repeats 
This is the accepted version of the following article: Kingo, O.S., \& Krøjgaard, P. (2015). Eighteen-month-olds' memory for short movies of simple stories, Scandinavian Journal of Psychology, which has been published in final form at https://dx.doi.org/10.1111/sjop.12201

the familiarity-preference during the $2^{\text {nd }}$ iteration. This pattern was confirmed by $t$-tests for each vocabulary group and iteration of the movie (see Table 1).

Figure 3

Table 1

\section{Discussion}

In the present study we investigated 18-month-olds' memory for short movies with simple storylines in the VPC paradigm. The infants showed a clear familiarity-preference after two weeks, thus revealing memory for the familiar movie. When this result is compared to similar VPC studies with comparable age-groups (e.g. Morgan \& Hayne, 2011) it confirms the prediction of the four-phase model (Bahrick \& Pickens, 1995) that a relatively long delay (remote memory) produces a familiarity preference.

Productive vocabulary was only marginally related to the magnitude of the familiarity-preference across the full test-phase, but correlated with changes in preference for the two movies from the $1^{\text {st }}$ to the $2^{\text {nd }}$ iteration, such that a lower vocabulary was associated with a shift towards a null-preference in the $2^{\text {nd }}$ iteration, while a higher vocabulary was associated with a familiarity-preference in both iterations. Such shifts from familiarity- towards novelty-preference within individual trials of VPC have been found before with infants (Snyder et al., 2008) and adults (Manns, Stark, \& Squire, 2000), and have been predicted by computational modeling as well (Sirois \& Mareschal, 2004). Yet how do we explain the 
This is the accepted version of the following article: Kingo, O.S., \& Krøjgaard, P. (2015). Eighteen-month-olds' memory for short movies of simple stories, Scandinavian Journal of Psychology, which has been published in final form at https://dx.doi.org/10.1111/sjop.12201

individual differences found in the present study? Our tentative interpretation is that: (1) at least some of the 18-month-olds in the present study are sensitive to the storyline of the presented videos; (2) infants with the higher vocabulary understand and remember the storyline in the visual stimuli better than those with a lower vocabulary; and (3) the "higher vocabulary" infants spend longer fixating the familiar movie because they are processing the meaningful (intention-action-outcome) information deeper than the "lower vocabulary" infants. In this interpretation it is not the case that the "lower vocabulary" infants "forget" the familiar movie from the $1^{\text {st }}$ to the $2^{\text {nd }}$ iteration. They simply spend less time processing the familiar movie because, with their more limited understanding of the storyline, there is less information to process. Consequently, they begin to orient their attention more towards the novel hence more interesting stimulus, or for this study at least to divide their attention evenly between the two movies.

Several other findings support this interpretation. First, as mentioned earlier, productive vocabulary has been found to correlate with memory for event sequences (Bauer \& Wewerka, 1995), as well as sequencing of event memory (McGuigan \& Salmon, 2004). Second, children with Specific Language Impairment (SLI) have been found to fixate less on semantically relevant areas of pictures accompanying a story than age-matched controls (Andreu, Sanz-Torrent, Olmos, \& MacWhinney, 2011). And third, our data and interpretation are in accordance with the Roder et al. (2000) finding that infants shifted from familiarity- to novelty preference across trials only for meaningful stimuli, while nonmeaningful stimuli did not produce a familiarity-preference prior to the novelty-preference. It thus seems that understanding the stimuli enhances or extends a familiarity-preference. Finally, one might object that the data-pattern in the present study could just be caused by difference in intelligence, which has long been thought to relate to vocabulary and correlate with novelty-preference (e.g. Fagan \& McGrath, 1981). However, the prediction following this logic would be that highly intelligent (and thus 
This is the accepted version of the following article: Kingo, O.S., \& Krøjgaard, P. (2015). Eighteen-month-olds' memory for short movies of simple stories, Scandinavian Journal of Psychology, which has been published in final form at https://dx.doi.org/10.1111/sjop.12201

high-vocabulary) infants would shift faster to a novelty-preference during the test than others (Fagan, 1984; Fagan \& McGrath, 1981), which is the opposite of what we find. Thus we believe our interpretation, however tentative, to be plausible.

Even though the present findings suggest that short dynamic movies with a storyline can meaningfully be combined with the VPC paradigm, the present study has some limitations. First of all, the sample of 24 infants is small. Even though several of our analyses reach significance, others are only marginally significant, and as such the clarity of the study would benefit from repetition with a larger sample. Second, it could be argued that, in spite of our efforts, the chosen stimuli are still simplistic and artificial compared to real world events. Furthermore, in a future study we plan to repeat the present study with the inclusion of groups of infants seeing abstract/meaningless videos, similar to the ones used in Roder et al. (2000). Currently we would predict that for such stimuli infants' vocabulary/conceptual development would not be related to novelty preference overall or changes in novelty preference during the test. Finally, we have just collected data for a related study in which we "disturb" the storyline of short cartoon movies to see how this affects infants' later recognition in a VPC task (Sonne, Kingo \& Krøjgaard, under review).

In the present study, 18-month-olds remembered short movies after two weeks retention. This memory manifested as a visual preference for the familiar movie, a finding which is consistent with predictions from the four-phase model suggested by Bahrick and Pickens (1995) for this age-group and retention interval. Importantly, a meaningful relation was found between vocabulary and changes in visual preference during an extended test-phase. These findings suggest that infants' understanding and memory of meaningful dynamic events with a storyline could be further explored in future VPC studies by comparing such stimuli directly to abstract "meaningless" dynamic stimuli. 
This is the accepted version of the following article: Kingo, O.S., \& Krøjgaard, P. (2015). Eighteen-month-olds' memory for short movies of simple stories, Scandinavian Journal of Psychology, which has been published in final form at https://dx.doi.org/10.1111/sjop.12201

References

Andreu, L, Sanz-Torrent, M, Olmos, J. G., \& MacWhinney, B. (2011). Narrative comprehension and production in children with SLI: An eye movement study. Clinical Linguistics \& Phonetics, 25 (9), 767-783.

Bahrick, L.E., Hernandez-Reif, M., \& Pickens, J.N. (1997). The effect of retrieval cues on visual preferences and memory in infancy: evidence for a four-phase attention function. Journal of Experimental Child Psychology, 67, 1-20.

Bahrick, L. E., \& Pickens, J.N. (1995). Infant memory for object motion across a period of three months: Implications for a four-phase attention function. Journal of Experimental Child Psychology, 59, 343-371.

Bahrick, L. E., Gogate, L. J., \& Ruiz, I. (2002). Attention and memory for faces and actions in infancy: The salience of actions over faces in dynamic events. Child Development, 73 (6), 1629-1643.

Bahrick, L. E., \& Newell, L. C. (2008). Infant discrimination of faces in naturalistic events: Actions are more salient than faces. Developmental Psychology, 44, 983-996. doi: 10.1037/00121649.44.4.983.

Baldwin, D. A. (2000). Interpersonal understanding fuels knowledge acquisition. Current Directions in Psychological Science, 9, 40-45.

Baldwin, D. A., Baird, J. A., Saylor, M. M., \& Clark, M. A. (2001). Infants parse dynamic action. Child Development 72(3). 708-717. Doi: 10.1111/1467-8624.00310. 
This is the accepted version of the following article: Kingo, O.S., \& Krøjgaard, P. (2015). Eighteen-month-olds' memory for short movies of simple stories, Scandinavian Journal of Psychology, which has been published in final form at https://dx.doi.org/10.1111/sjop.12201

Bard, K. A., Todd, B. K., Bernier, C., Love, J, \& Leavens, D. A. (2006). Self-awareness in human and chimpanzee infants: What is measured and what is meant by the mark and mirror test? Infancy, 9, 191-219.

Bauer, P. J., \& Wewerka, S. S. (1995). One- to two-year-olds' recall of events: The more expressed, the more impressed. Journal of Experimental Child Psychology, 59, 475-496.

Conway, M. A., \& Pleydell-Pearce, C. W. (2000). The construction of autobiographical memories in the self-memory system. Psychological Review, 107 (2), 261-288.

Courage, M. L., \& Howe, M. L. (1998). The ebb and flow of infants' attentional preferences: Evidence for long-term memory in 3-month-olds. Journal of experimental child psychology, 70, 26-53.

Courage, M. L., \& Howe, M. L. (2001). Long-term retention in 3.5-month-olds: Familiarization time and individual differences in attentional style. Journal of experimental child psychology, 79, 271-293.

Fagan, J. F. (1984). The intelligent infant: Theoretical implications. Intelligence, 8, 1-9.

Fagan, J. F., \& McGrath, S. K. (1981). Infant recognition memory and later intelligence. Intelligence, 5, 121-130.

Gopnik, A, \& Meltzoff, A. N. (1987). The development of categorization in the second year and its relation to other cognitive and linguistic developments. Child Development, 58, 1523-1531.

Gopnik, A, \& Meltzoff, A. N. (1992). Categorization and naming: basic-level sorting in eighteen-montholds and its relation to language. Child Development, 63, 1091-1103.

Hayne, H. (2004) Infant memory development: Implications for childhood amnesia. Developmental Review, 24, 33-73. doi: 10.1016/j.dr.2003.09.007.

Houston-Price, C., \& Nakai, S. (2004). Distinguishing novelty and familiarity effects in infant preference procedures. Infant and Child Development, 13, 341-348. 
This is the accepted version of the following article: Kingo, O.S., \& Krøjgaard, P. (2015). Eighteen-month-olds' memory for short movies of simple stories, Scandinavian Journal of Psychology, which has been published in final form at https://dx.doi.org/10.1111/sjop.12201

Kingo, O.S., Staugaard, S.R., \& Krøjgaard, P. (2014). Three-year-olds' memory for a person met only once at the age of 12 months: Very long-term memory revealed by a late-manifesting novelty preference. Consciousness and Cognition, 24, 49-56, doi: 10.1016/j.concog.2013.12.011.

Lewis, M., Brooks-Gunn, J. (1979). Social cognition and the acquisition of self. New York: Plenum.

Manns, J. R., Stark, C. E. L., \& Squire, L. R. (2000). The visual paired-comparison task as a measure of declarative memory. Proceedings of the National Academy of Sciences, 97, 12375-12379.

McGuigan, F., \& Salmon, K. (2004). Time to talk: The influence of the timing of adult-child talk on children's event memory.

Meltzoff, A. N. (1995). Understanding the intentions of others: Re-enactment of intended acts by 18month-old children. Developmental Psychology, 31, 838-850.

Moore, C., Mealiea, J., Garon, N., \& Povinelli, D. (2007). The development of body self-awareness. Infancy, 11, 157-174.

Morgan, K., \& Hayne, H. (2011). Age-related changes in visual recognition memory during infancy and early childhood. Developmental Psychobiology, 53, 157-165.

Oates, J., \& Grayson, A. (Eds.) (2004). Cognitive and Language Development in Children. MA: Blackwell Publishing.

Reese, E. (1999). What children say when they talk about the past. Narrative Inquiry, 9 (2), 215-241.

Richmond, J., Colombo, M., \& Hayne, H. (2007). Interpreting visual preferences in the visual pairedcomparison task. Journal of Experimental Psychology: Learning, Memory, and Cognition. 33 (5). 832-831. 
This is the accepted version of the following article: Kingo, O.S., \& Krøjgaard, P. (2015). Eighteen-month-olds' memory for short movies of simple stories, Scandinavian Journal of Psychology, which has been published in final form at https://dx.doi.org/10.1111/sjop.12201

Richmond, J., Sowerby, P., Colombo, M., \& Hayne, H. (2004). The effect of familiarization time, retention interval, and context change on adults' performance in the visual paired comparison task. Developmental Psychobiology, 44, 146-155.

Roder, B. J., Bushnell, E. W., \& Sasseville, A. M. (2000). Infants' preferences for familiarity and novelty during the course of visual processing. Infancy, 1 (4), 491-507.

Sirois, S., \& Mareschal, D. (2004). An interacting systems model of infant habituation. Journal of Cognitive Neuroscience, 16, 1352-1362.

Snyder, K. A., Blank, M. P., \& Marsolek, C. J. (2008). What form of memory underlies novelty preferences? Psychonomic Bulletin \& Review, 15, 315-321. doi: 10.3758/PBR.15.2.315.

Sonne, T., Kingo, O.S., \& Krøjgaard, P. (under review). Event boundaries have a privileged status in 20 month-olds' memory for cartoons, but not in 16-month-olds.

Tomasello, M. (1999). The cultural origins of human cognition. Cambridge, MA: Harvard University Press.

Waxman, S.R., \& Gelman, S.A. (2010). Different kinds of concepts and different kinds of words: what words do for human cognition. In Marechal, D.; Quinn, P.C. \& Lea, S.E. (Eds.) The making of human concepts. (1st ed. pp. 99-130). Oxford University Press. 
This is the accepted version of the following article: Kingo, O.S., \& Krøjgaard, P. (2015). Eighteen-month-olds' memory for short movies of simple stories, Scandinavian Journal of Psychology, which has been published in final form at https://dx.doi.org/10.1111/sjop.12201

Figure 1

Still-pictures of the two stimuli movies.

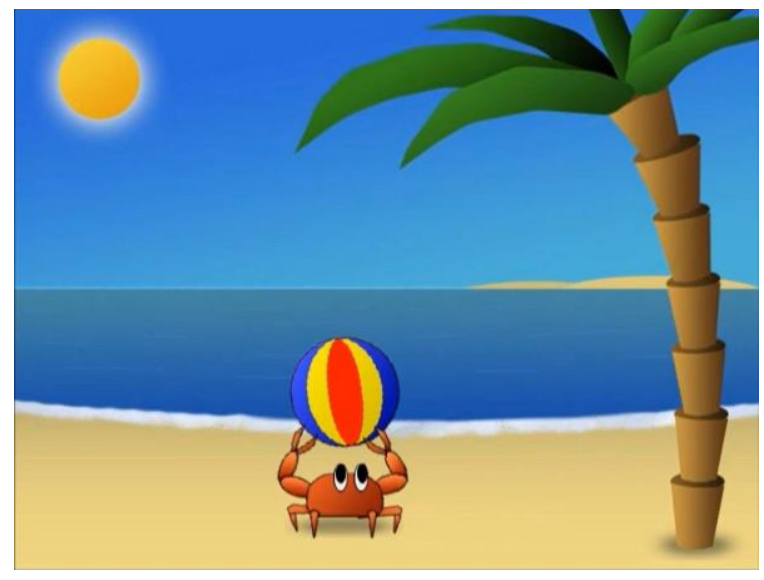

"Crab"
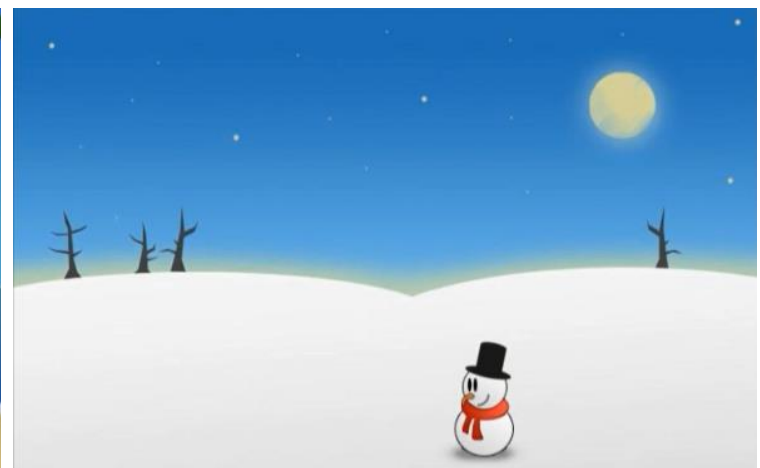

"Snowman" 
This is the accepted version of the following article: Kingo, O.S., \& Krøjgaard, P. (2015). Eighteen-month-olds' memory for short movies of simple stories, Scandinavian Journal of Psychology, which has been published in final form at https://dx.doi.org/10.1111/sjop.12201

Figure 2

Graph of proportional looking to the novel movie during both iterations of the movies in the test-phase.

Error bars: +/- $1 \mathrm{SE}$.

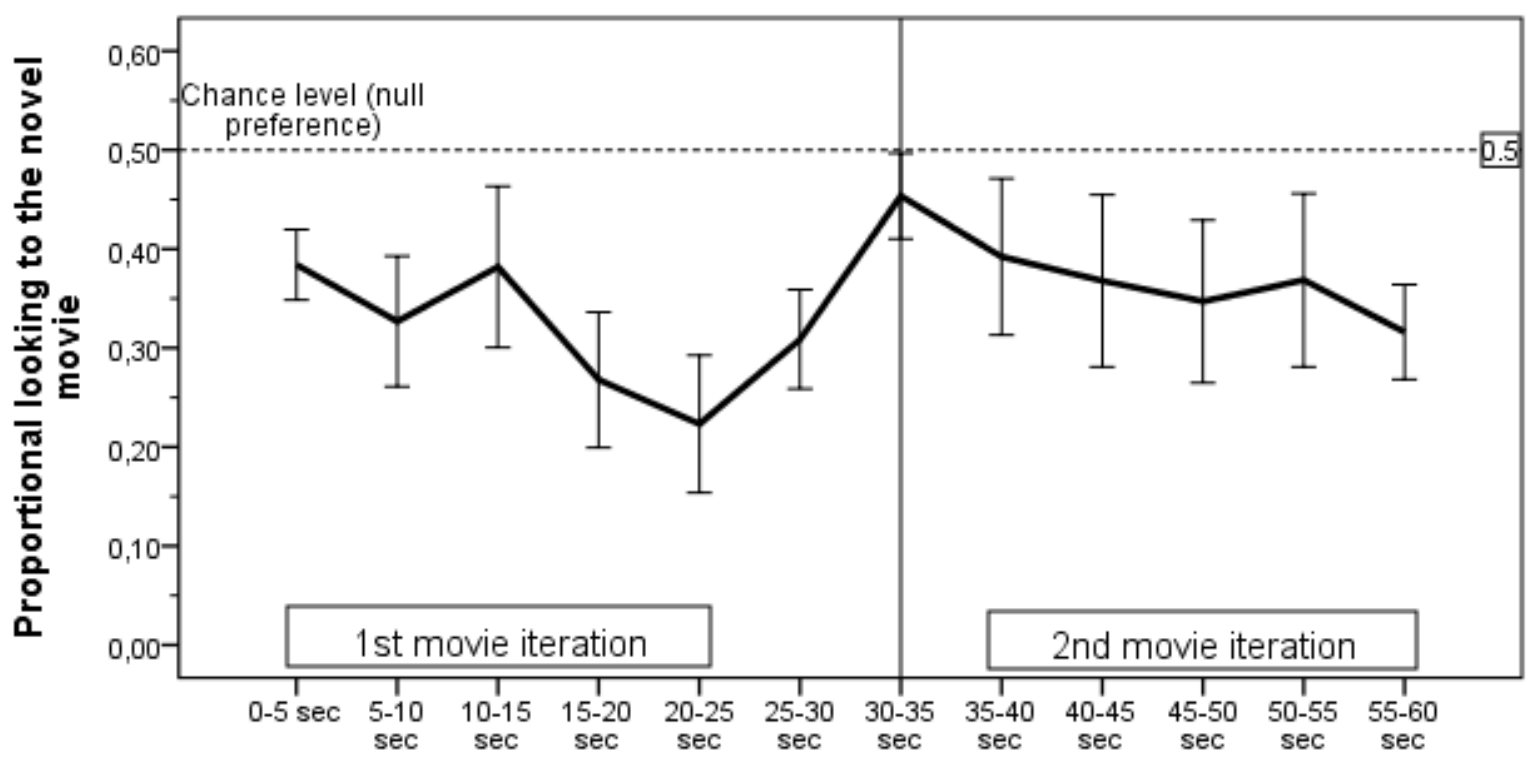


This is the accepted version of the following article: Kingo, O.S., \& Krøjgaard, P. (2015). Eighteen-month-olds' memory for short movies of simple stories, Scandinavian Journal of Psychology, which has been published in final form at https://dx.doi.org/10.1111/sjop.12201

Figure 3

Graph of proportional looking to the novel movie during both iterations of the movies in the test-phase, split into lower and higher vocabulary groups. Error bars: +/- $1 \mathrm{SE}$.

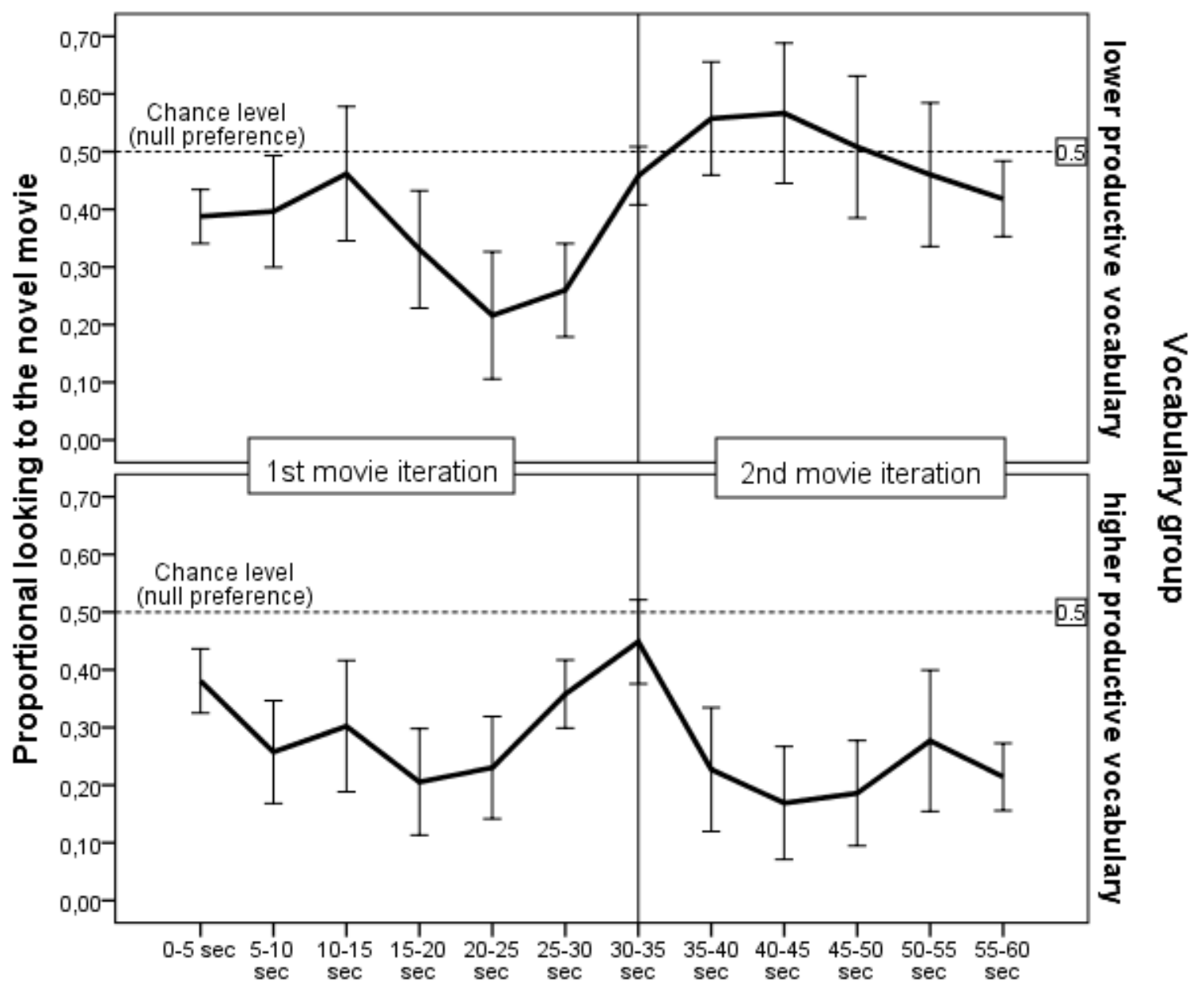


This is the accepted version of the following article: Kingo, O.S., \& Krøjgaard, P. (2015). Eighteen-month-olds' memory for short movies of simple stories, Scandinavian Journal of Psychology, which has been published in final form at https://dx.doi.org/10.1111/sjop.12201

Table 1

Display of means of the proportional looking to the novel movie and $p$-values for one-sample $t$-tests against the chance level (.5) for each vocabulary group and both iterations of the movie.

Iteration

\begin{tabular}{lll}
\cline { 2 - 3 } Vocabulary group & 2nd
\end{tabular}
Lower $(N=12)$
$M=.34, p<.05, r=.57$
$M=.50, p>.9, r=.02$
Higher $(N=12)$
$M=.29, p<.01, r=.75$
$M=.25, p<.001, r=.83$ 